\title{
Simulation and mock code: A safe way for nursing students to learn
}

\author{
Lynn C. Simko' ${ }^{1}$ Rosanna Henry ${ }^{1}$, Kathleen A. McGinnis ${ }^{2}$, Amber L. Kolesar ${ }^{1}$ \\ 1. School of Nursing, Duquesne University, Pittsburgh, USA. 2. Independent statistician, USA. \\ Correspondence: Lynn C. Simko. Address: School of Nursing, Duquesne University, 600 Forbes Avenue, Pittsburgh, PA \\ 15282, USA. Email: simko@duq.edu
}

Received: March 6, 2014

Accepted: March 31, 2014

Online Published: May 4, 2014

DOI : $10.5430 /$ jnep.v4n7p95

URL: http://dx.doi.org/10.5430/jnep.v4n7p95

\section{Abstract}

Introduction: It is better for students to experience stressful clinical events in a simulation lab rather than to experience the event in a clinical setting where a patient's life is at stake.

Aim: The aim of this study was to discover if participation in a mock code with a simulation manikin would result in increased knowledge in nursing students as well as a safe way to learn the nursing interventions required during a code.

Methods: Students were given a 10-item multiple choice pre-test. The Advanced Cardiac Life Support guidelines were reviewed in a lecture format, readings regarding cardiac resuscitation and computer assisted instruction involving multiple code situations were assigned. Students were assigned a role and were given the expectations and activities of each role. The code was then experienced and video-taped with a simulation manikin. Debriefing was experienced and students completed a post-test.

Results: Scores were significantly greater on the post-test than on the pre-test overall (7.9 vs 5.2; $p<.001$ ), for the traditional undergraduate (7.6 vs 5.2; $p<.001$ ) and second degree students (8.6. vs. 5.5; $p<.001)$. The post-test scores were significantly greater for second degree students than the traditional undergraduates (8.4 vs $7.5 ; p<.001)$. The simulation experience is truly a safe environment for the nursing student to learn the nursing interventions needed during a real code situation.

\section{Key words}

Mock code, Simulation, Traditional BSN students, Second degree nursing students, Advanced Cardiac Life Support

\section{I ntroduction}

It is better for students to experience stressful clinical events in a simulation lab rather than to experience the event in a clinical setting where a patient's life is at stake. In the last decade, simulation as a teaching tool for student nurses has proliferated in the literature. As patient acuity rises and clinical teaching sites becoming increasingly scarce, nursing educators are turning to simulation technology as an effective teaching tool ${ }^{[1,2]}$. As described by Cannon-Diehl ${ }^{[3]}$, nursing education, as we know it, is changing at a rapid pace. Virtual reality and a continuum of various types of simulation have evolved, emerged and infiltrated healthcare education at all levels. Simulation has been used for decades in education and personnel evaluation in many disciplines and professions including the nuclear power and aviation industries. In the 
1980's, with powerful personal computers and software innovations, the anesthesia profession developed some of the earliest patient mannequins, which contributed significantly to the development of the fully interactive patient simulators that exist today ${ }^{[4]}$.

The Institute of Medicine (IOM) report discusses how simulation training is recommended as a strategy that can be used to prevent errors in the clinical setting. The report also states that “...health care organizations and teaching institutions should participate in the development and use of simulation for training novice practitioners, problem solving, and crisis management, especially when new and potentially hazardous procedures and equipment are introduced” ${ }^{[5]}$. In Sanford's ${ }^{[6]}$ publication she explains that simulation is done in an artificial situation so that students will later be able to practice safely in the clinical setting.

\subsection{Review of the literature}

A clinical simulation is an event or situation made to resemble clinical practice in nursing education as closely as possible. Soar, et al. ${ }^{[7]}$ from the European Resuscitation Council Guidelines for Resuscitation, discusses simulation as an essential part of resuscitation training. Mock Code is defined as a simulation exercise with a mannequin/human patient simulator with no respiratory effort and/or no carotid pulse ${ }^{[7,8]}$. It is through this simulation that students are able to learn and practice in an arena that cannot cause harm to an actual patient ${ }^{[2]}$. Full-scale patient simulations include high-fidelity, sophisticated simulators that provide a high level of interactivity and realism for the learner ${ }^{[9]}$. It has been described by Jeffries ${ }^{[9]}$ as "an ideal setting for students to develop psychomotor skills without any risk of inflicting harm to patients". Using human patient simulators to practice clinical skills provides students with a safe environment that fosters autonomy, independence, and the development of analytical skills. Simulation helps to create an experience that the student nurse may not encounter during their traditional clinical. It provides a way to increase safety and decrease errors, improve clinical judgment, and is useful for teaching and evaluating specific clinical skills ${ }^{[1,10]}$. During simulation, the learner must use a higher order of learning rather than simply mimicking the teacher role model; this requires decision-making and critical thinking skills ${ }^{[11]}$.

Simulation has been used in schools of nursing since the 1950s, but only recently has research sought to evaluate the efficacy of human patient simulators in nursing education ${ }^{[12,13]}$. Jeffries ${ }^{[9]}$ also identified the need for rigorous research designs to evaluate learning outcomes. She went on to state that research is needed to identify the hallmarks of a good simulation, the role of the teacher in development and implementation, and the effect of simulations on student learning.

Joyce and Weil ${ }^{[14]}$ identified a 4-phase teaching model for simulation: phase one includes an overview of the simulation as well as the topic to be covered; Phase two involves lecture, preparatory assignments, review of technical nursing skills, and assignment of roles. Phase three is the simulation experience, and phase four is debriefing. In their mock code simulation implementation, Spunt and researchers ${ }^{[15]}$ utilized a lecture format and then had student identify their roles prior to the start of their simulation. They noted that by assuming the roles of different disciplines, the students are given a great appreciation of the multidisciplinary approach to healthcare. It is suggested that students have preparatory assignments to read and are encouraged to review their notes from the lecture that their simulation would be pertaining to. Some simulations give the student pre-assigned roles. Kardon-Edgren and others ${ }^{[16]}$ also utilized learning modules and roles prior to simulation. Peppler, Dannhausen, and Willock ${ }^{[13]}$ had utilized a CD-Rom with the necessary information for their students pre-simulation.

The simulation itself is often videotaped so that the participants can view it during debriefing as an added learning tool. While some students may initially be uncomfortable in front of a video camera, once involved in the mock code simulation they often quickly relax and lose their self-awareness ${ }^{[17]}$. This can be an effective tool as participants are able to deconstruct events and errors that unfolded during the scenario, as well as acquire new information to improve future practice $^{[18]}$. 
Starkweather and Kardon-Edgren ${ }^{[17]}$ noted that it is not solely the use of simulation, but the techniques employed with simulation that can improve the teaching-learning experience. Debriefing is one of the techniques identified to help improve the simulation teaching-learning experience. Often, a video of the simulation is played back for the participants. Debriefing "gives learners the opportunity to think critically about their performance, deconstruct events and errors that unfold during the scenario, and acquire new information to improve subsequent practice" ${ }^{[18]}$. Debriefing is used as a tool to clarify positive or negative feedback, allow students to verbalize their feelings about the simulation experience, and evaluate their own behaviors, communication patterns, and assessment skills. By watching the videotape of their performance, students may be able to identify plans for future improvement ${ }^{[11]}$. Spunt et al. ${ }^{[15]}$ noted that during debriefing, values, attitudes, emotional reactions, stress, and feelings regarding death, postmortem care, and family crises can be discussed in an open format.

Simulation has shown to be an effective teaching tool, and is being utilized more as clinical sites become increasingly scarce. Having the student nurse experience their first "Code" in a safe simulation experience is indeed a safe way to practice Advanced Cardiac Life Support (ACLS) without harming a real patient. The mock code simulation helps to prepare student nurses for the "real thing" when it does occur.

\subsection{Statement of the research questions}

Although simulation has been used as a means of teaching nursing students for decades, advances in technology have taken simulation to an entirely new level. A patient simulator known as SimMan ${ }^{\circledR}$ Human Patient Simulator by Laerdal is currently used by the Northeast University School of Nursing for providing baccalaureate level nursing students with realistic patient scenarios to practice their critical thinking skills, motor skills and determine their level of knowledge. According to Terman ${ }^{[19]}$, simulation laboratories are used to help student acquire knowledge, critical thinking, and psychomotor skills and develop confidence in their abilities. By using simulation laboratories as a learning resource, students can take theoretical concepts acquired in a safe and supportive learning environment into the unforgiving environment of clinical patient care. Thus simulation and mock code are a safe way to learn.

The research questions for this study are as follows:

- Does the use of SimMan ${ }^{\circledR}$ in having students perform a mock code increase their knowledge of code procedures and data application?

- $\quad$ Do scores on pre mock code tests and post mock code tests differ between traditional nursing students and $2^{\text {nd }}$ degree students?

\subsection{Aim}

The aim of this study was to discover if participation in a mock code with a simulation manikin would result in increased knowledge in nursing students as well as a safe way to learn the nursing interventions required during a code. The ability of working with other disciplines (i.e. respiratory therapists, anesthetist, nursing supervisor etc.) will help enhance critical thinking and make for a "real life" code.

\section{Methods}

\subsection{Study design and setting}

A prospective pre-test post-test study design was implemented. The "mock code" simulation was introduced into a junior level medical-surgical course for traditional undergraduate baccalaureate school of nursing (BSN) students as well as in the accelerated second degree nursing program (ASDNP), in Duquesne University, a metropolitan university in the Northeastern United States. Duquesne University is a private, non-profit Catholic University. Duquesne University's total 
enrollment is approximately 10,000 students, the School of Nursing has a graduate enrollment of approximately 254, with the undergraduate enrollment at approximately 560.

\subsection{Sample}

The sample selection for this study was from junior baccalaureate level traditional and $2^{\text {nd }}$ degree nursing students in their second Medical/Surgical Nursing course. Institutional Review Board (IRB) permission was obtained in order to protect the students' right in that consent to participate, and the results of the pre-test post-test will not affect their final grade in the course. The major focus of this second junior level medical-surgical course material was on the acute care of adult patients in the intensive care unit (ICU) setting. Throughout the course the students learned how to interpret cardiac rhythm strips. Upon the completion of this material the students were then introduced into the treatment of lethal arrhythmias. Lethal arrhythmias can result in a "Code" which is when a patient no longer has a pulse and needs immediate assistance (the patient can either stop breathing or his/her heart stops functioning). This is a huge high stake event in the medical field, which will determine whether a patient lives or dies. It is always better to experience your first "Code" in a controlled setting, where the worst thing that can happen is that the mannequin dies and not a real individual.

The school of nursing, in this metropolitan northeastern university purchased a SimMan ${ }^{\circledR}$ Human Patient Simulator by Laerdal. For the first three years in which we had used SimMan ${ }^{\circledR}$ for these mock codes, feedback from the students was that it was a positive experience, that they had indeed learned quite a bit, and that they felt ready for a real "code". This was all based on anecdotal comments from the students. This researcher wanted to quantify the impact that the $\operatorname{SimMan}{ }^{\circledR}$ mock code experience had upon the students.

\subsection{Data collection instrument}

Permission was obtained from the American Heart Association (AHA) to use 10 of the test items on their Advanced Cardiac Life Support (ACLS) exam. The items were all multiple choice, four of the questions required the students to identify a rhythm in order to correctly answer the question. The other 6 questions required application of the ACLS algorithms. The pre-test and the post-test were identical exams.

\subsection{Procedures}

After approval from the IRB committee of this metropolitan northeastern university the simulation project was then introduced to the nursing students. They were informed that their participation was voluntary, that at any time they want to withdraw from the study, they were permitted. The scores that they obtain on the pre-test and post-test will, in no way, affect their final grade in this course. They were not told that the pre-test was identical to the post-test. Therefore the sequence of events were as follows:

1) Students gave written informed consent to participate in this mock code at the beginning of the semester.

2) Students then took the pre-test.

3) The students were then assigned roles which they were to play in the mock code (See Table 1).

4) Students were then given lectures and readings which contained ACLS procedures/algorithms.

5) Specific instructions for each individual role were given immediately prior to the actual participation in the mock code simulation. (i.e. showing the critical care RN how the defibrillator works etc.).

6) Because SimMan ${ }^{\circledR}$ is capable of responding to the student's interventions or lack of appropriate intervention, his heart rhythm would change as well as his blood pressure, oxygen saturation and respiratory rate. Therefore each mock code was different from the others and was captured by videotaping. 
Table 1. Mock Code-Assigned Roles

\begin{tabular}{|ll|}
\hline First Response MD & $\begin{array}{l}\text { Manages the code using the ACLS algorithms; decides outcome of the code. } \\
\text { MD \#2 }\end{array}$ \\
Primary RN & $\begin{array}{l}\text { Assigned to patient; recognizes/discovers and calls code; initiates CPR but relinquishes to code } \\
\text { team; provides patient information to MD (has the Chart) Will help assume Respiratory } \\
\text { Therapist duties if needed. }\end{array}$ \\
Second Response RN & $\begin{array}{l}\text { Brings resuscitative equipment; places patient on monitor; does CPR. May help nursing } \\
\text { supervisor notify/deal with family. }\end{array}$ \\
Critical Care RN & $\begin{array}{l}\text { Brings resuscitative equipment; places patient on monitor if not already on the monitor; } \\
\text { Coordinates the code; “mans” the crash cart; responsible for defibrillation/cardioversion. }\end{array}$ \\
Anesthetist & $\begin{array}{l}\text { Intubates/secures the airway } \\
\text { Respiratory Therapist \#1 }\end{array}$ \\
Assesses ventilatory status; does ABGs, blood draws for lab work; assists with CPR-maintains \\
vespiratory Therapist \#2 & $\begin{array}{l}\text { Assesses ventilatory status; does ABGs, blood draws for lab work, assists with CPR-maintains } \\
\text { ventilation. }\end{array}$ \\
IV Team RN & Secures an IV access (initiates an infusion/assesses adequacy of present infusion); prepares and \\
administers medications. & Records ALL resuscitative activities on Code Sheet; notifies attending MD; notifies/deals with \\
farsing Supervisor & Act accordingly.
\end{tabular}

The mock code roles state that the first response MD and MD \#2 decides the outcome of the code, however before the start of each mock code, students are informed as a group that each is responsible for "chiming in" as to what cardiac rhythm they think SimMan ${ }^{\circledR}$ is in, and, if the MDs don’t order an appropriate treatment for the problem, then again each student must suggest other treatment options. This creates a great learning experience for all students regardless of their role in the mock code. The students who had the roles of the first response MD\#1 and MD\#2 were permitted to bring their copies of the ACLS algorithms and refer to them when needed in the mock code. The assignment of the roles fosters an interdisciplinary collegiality for the student nurses. They learn the importance of all disciplines which interact during a code, from the respiratory therapist to the MDs. They begin to appreciate that one role alone can not have a successful outcome in a code situation and that all disciplines must work together in a calm, yet purposive way in order to achieve the best results for the patient. The mock code then ended with either SimMan ${ }^{\circledR}$ surviving or expiring.

- Debriefing of videotaped simulation occurred immediately after the mock code. This consisted of an informal debriefing of the video and actions taken by the students. Students could make comments while the tape was running, often discussion ensued and we worked together to resolve issues students raised before continuing to view the remainder of the video. Students conducted a great deal of self-analysis. The simulation and debriefing took from 40 to 60 minutes per group.

- After all debriefing was completed, students took the post-test which consisted of the same 10 questions as on the pre-test. After completion of the post-test we reviewed the test as a group and further discussion ensued.

\subsection{Data analysis}

Pre and post-test scores were on a scale from 0-10. Final grades were on a scale of 0-100. Analyses were carried out using Stata 9.0 (College Station, TX). Paired $t$-tests were used to compare test scores between pre and post-tests. $T$-tests were used to compare test scores between the undergraduate and 2nd degree students. We also generated a change in score from pre-test to post-test, by subtracting the pre-test score from the post-test score. We then compared the change in score between the undergraduate and 2nd degree students using a $t$-test.

\section{Results}

Scores were statistically significantly greater on the post-test than the pre-test overall (7.9 v.s $5.3 ; p<.001$ ), and for undergraduate (7.6 vs. 5.2; $p<.001$ ) and 2nd degree students (8.6 vs. 5.5; $p<.001)$. See Table 2 for a summary of scores. 
Table 2. Comparison of Pre and Post-test Scores

\begin{tabular}{lllll}
\hline & \multirow{2}{*}{ N } & Mean (SD) & \\
\cline { 3 - 5 } & & Pre-Test & Post-Test & P-Value \\
\hline Overall & 190 & $5.3(1.9)$ & $7.9(1.7)$ & $<.001$ \\
Undergraduate & 135 & $5.2(1.8)$ & $7.6(1.7)$ & $<.001$ \\
$2^{\text {nd }}$ Degree & 55 & $5.5(2.0)$ & $8.6(1.6)$ & $<.001$ \\
\hline
\end{tabular}

Table 3. Comparison of Scores between Undergraduate and $2^{\text {nd }}$ Degree Students

\begin{tabular}{llll}
\hline & \multicolumn{2}{l}{ Mean (SD) } & P-Value \\
\cline { 2 - 3 } & Undergraduate & $2^{\text {nd }}$ Degree & .11 \\
\hline Pre-Test & $5.2(1.8)$ & $5.6(2.1)$ & $<.001$ \\
Post-Test & $7.5(1.6)$ & $8.4(1.8)$ & .03 \\
Change in Score* & $2.4(1.9)$ & $3.1(2.1)$ & \\
\hline
\end{tabular}

*Change in score equal post-test score minus pre-test score.

For the pre-test, scores were not statistically significantly different between undergraduate and $2^{\text {nd }}$ degree students (5.2 and 5.6; $p=.11$ ); however scores were statistically significantly greater for $2^{\text {nd }}$ degree students on the post-test (8.4 vs. 7.5; $p$ $<.001)$. Additionally, the change in score from pre to post-test was statistically significantly greater for the $2^{\text {nd }}$ degree students than for undergraduate students (3.1 vs. 2.4; $p=.03$ ). See Table 3 for a summary of scores.

\section{Discussion}

The use of SimMan ${ }^{\circledR}$ in having students perform a mock code to increase their knowledge of code procedures and data application, is supported by the statistically significant increase in the scores from pre-tests to post-test overall and for the traditional and second degree nursing students. The test contained 6 multiple choice questions which required application of the ACLS algorithms along with 4 items which required rhythm strip interpretation and application of the ACLS algorithms. The researchers wanted to use a standardized/reliable/valid exam in order to quantify that the preparation for the mock code simulation and the simulation itself was indeed beneficial for the students. In the debriefing by the students, many stated that they would do so much better if they could do another mock code, and that they felt that they were well prepared for a "real code" on the clinical unit. Those students who had observed a code in the clinical setting, stated that the code in the simulation lab was "just like" the real thing, with the appropriate roles, the doctors, respiratory therapist and the critical care RN. Nagle et al. ${ }^{[4]}$ explained that simulation as a teaching and learning methodology is being embraced by nursing in academic and practice setting to provide innovative educational experiences to assess and promote teamwork, develop clinical competency, and improve care processes. The research findings by Leighton and Scholl ${ }^{[20]}$ support the findings of this study in that confidence in code response increased and fear in encountering a code decreased following the simulated clinical experience.

As with Leighton and Scholl ${ }^{[20]}$, during the debriefing sessions the students watched their actions, identified strengths and weaknesses, communicated concerns, clarified misconceptions and communicated concerns about the experience. Some comments were "I can't believe that no one is doing CPR", and "Can you believe that we forgot to place the backboard under SimMan ${ }^{\circledR}$ ?” The debriefing sessions were learner-driven and varied in the time required to complete the debriefing.

Pre-test scores were not statistically significantly different between BSN and second degree students, although they were slightly higher for the second degree students. However, post-test scores were statistically significantly higher for the second degree students than for traditional BSN students. At this northeastern university, we have found that the second degree students are more conscientious, motivated, self-directed and that their scores on exams were usually higher than the traditional BSN students. The simulation related situations were no different than the academic testing, second degree students usually did better in the mock code simulation settings. The traditional BSN students may require more simulations than the second degree students. 


\section{Nursing education implications}

As noted in several manuscripts ${ }^{[3,4,20]}$ clinical simulation takes a great deal of time for the academician in preparation for the simulation, conducting the simulation and debriefing after the simulation. This northeastern university has approximately 100 juniors and 40 second degree students, taking 9 to 11 students in each mock code simulation takes approximately 13 to 16 hours at the minimum. All of which does not count on preparing the clinical lab, cleaning up after the simulations etc. all of which takes additional time. Cannon-Diehl ${ }^{[3]}$ discussed that "today's consumers of education have higher expectations for curricula. Healthcare is evolving with fewer resources and more complex roles. Advancing technology is creating a dependence on simulation as a teaching and learning strategy. Society in general, in the form of both public and professional organizations, supports simulation as a viable teaching and learning strategy". With all of the time required for simulation experiences for students the educator must gain organizational commitment for this innovative teaching method due to the significant resources required for program implementation and ongoing support ${ }^{[4]}$. Clinical sites are also using mannequins to review newborn, pediatric and adult mock codes ${ }^{[21-27]}$. The educational advantages that these institutions cite is that they have identified targets for educational intervention to improve cardiopulmonary resuscitation and, ideally, outcomes.

Video taping of the simulation for the students to watch during the debriefing is the ideal aid for educators. During the simulation, the time goes very quickly and the students are really not aware of things that they said or did or did not do. Therefore the video taping of the simulation is vital for a productive debriefing.

Educators should be cognizant that the traditional undergraduate BSN student may need additional experience with the mock code simulation. Their final score on the post-test was 7.6 or $76 \%$, while the second degree students had a post-test score of 8.6 or $86 \%$. As educators we might want to have the traditional undergraduate BSN student go through the mock code simulation twice, thus reinforcing what they had learned in the debriefing and simulation exercise. The timing of this second mock code would need to be investigated/researched. Should they immediately go through the second mock code simulation after the debriefing of the first mock code simulation, or should there be additional time between simulations for the students to prepare themselves for the second mock code? Anecdotally, the students stated that they would do so much better on the code if they could have a second chance. Again, this requires additional resources and time, as discussed previously.

Finally, as educators we want to emphasize that the debriefing session after the mock code, or any simulation, is also where the true learning tales place. Other authors ${ }^{[11,17,18]}$, make strong points as to the value of debriefing. This debriefing session, especially if the simulation is videotaped and watched during the debriefing, allows the students to ask questions, clarify misconceptions, reflect on the experience, give a chance to synthesize and reflect on the decisions that were made during the scenario, critically analyze the simulation and develop critical thinking skills. The students now appreciate the importance of good communication skills during the mock code. They realize that interdisciplinary communication is vital in the success of the mock code. It is this northeastern university's experience that the debriefing sessions after simulation is where the true learning can be found.

\section{Conclusions}

This study showed that there was a significant amount of learning for the traditional and second degree nursing students who participated in this mock code simulation experience. The video taped debriefing experience was a great learning tool for the nursing students. They were able to deconstruct events and errors that unfolded during the scenario, as well as acquire new information to improve future practice ${ }^{[18]}$.

The second degree nursing students did better with the mock code simulation than those in the traditional undergraduate program. SimMan did not expire with the second degree nursing students, where as with some of the traditional BSN 
students, he did succumb to inadequate treatment from some of the groups. This research again reflected that second degree students do better academically than traditional BSN students. This has been noticed anecdotally at this northeastern university. Further research is needed in this area to reflect whether there is indeed a difference in academic/simulation performance for second degree nursing students vs. traditional BSN nursing students. And finally, the mock code simulation is a safe place for nursing students to learn what nursing interventions are needed in a code situation.

\section{References}

[1] Bantz D, Dancer M, Hodson-Carlton K, Van Hove S. A daylong clinical laboratory: From gaming to high-fidelity simulators. Nurse Educator. 2007; 32(6): 274-277. PMid:17998857 http://dx.doi.org/10.1097/01.NNE.0000299476.57185.f3

[2] Blum CA, Parcells DA. Relationship between high-fidelity simulation and patient safety in prelicensure nursing education: A comprehensive review. Journal of Nursing Education. 2012; 51(8): 429-435.

[3] Cannon-Diehl MR. Simulation in healthcare and nursing: State of the science. Critical Care Nursing Quarterlies. 2009; 32(2): 128-136. PMid:19300077 http://dx.doi.org/10.1097/CNQ.0b013e3181a27e0f

[4] Nagle BM, McHale JM, Alexander GA, French BM. Incorporating scenario-based simulation into a hospital nursing education program. The Journal of Continuing Education in Nursing. 2009; 40(1): 18-25. http://dx.doi.org/10.1097/CNQ.0b013e3181a27e0f

[5] Kohn LT, Corrigan JM, Donaldson MS. (Eds). To err is human: building a safer health system A report of the Committee on Quality of Health Care in America, Institutes of Medicine. Washington, DC: National Academy Press. 2000.

[6] Sanford PG. Simulation in nursing education: A review of the research. The Qualitative Report. 2010; 15(4): 1006-1011.

[7] Soar J, Monsieurs KG, Balance JHW, Barelli A, Biarent D, Greif R, et al. European resuscitation council guidelines for resuscitation 2010 Section 9. Principles of education in resuscitation. Resuscitation. 2010; 81: 1434-1444. PMid:20956044 http://dx.doi.org/10.1016/j.resuscitation.2010.08.014

[8] Szogedi I, Zrinyi M, Betlehem J, Siket Ujvarine A, Toth, H. Training nurses for CPR: Support for the problem-based approach. European Journal of Cardiovascular Nursing. 2010; 9: 50-56. PMid:19892601 http://dx.doi.org/10.1016/j.ejcnurse.2009.09.003

[9] Jeffries, P. Chapter 8: Designing simulations for nursing education. In Oermann, M.T. \& Heinrich, K.T. (Eds). Annual Review of Nursing Education. Volume 4 New York, NY: Springer Publishing. 2006. 161-177.

[10] Gates MG, Parr MB, Hughen JE. Enhancing nursing knowledge using high-fidelity simulation. Journal of Nursing Education. 2012; 51(1): 9-15. PMid:22085206 http://dx.doi.org/10.3928/01484834-20111116-01

[11] Dreifuerst, KT. Using debriefing for meaningful learning to foster development of clinical reasoning in simulation. Journal of Nursing Education. 2012; 51(6): 326-333. PMid:22495923 http://dx.doi.org/10.3928/01484834-20120409-02

[12] Norman J. Systematic review of the literature on simulation in nursing education. ABNF J. 2012; April 2012.

[13] Peppler J, Dannhausen J, Willock K.. Sim-Man: Not your grandma’s nursing education. NSNA Imprint. 2007; 54(3): 46-50, 52.

[14] Joyce B, Weil M. Learning from simulations: training and self-training. In: Models of Teaching. 5th ed. Needam Heights, MA: Allyn \& Bacon. 1996; 353-363.

[15] Spunt D, Foster D, Adams K. Mock code: A clinical simulation module. Nurse Educator. 2004; 29(5): 192-194. PMid:15371759 http://dx.doi.org/10.1097/00006223-200409000-00009

[16] Kardong-Edgren S, Starkweather A, Ward L. The integration of simulation into a clinical foundations of nursing course: Student and faculty perspectives. International Journal of Nursing Education Scholarship. 2008; 5(1): Article 26. http://dx.doi.org/10.2202/1548-923X.1603

[17] Starkweather A, Kardong-Edgren S. Diffusion of Innovation: Embedding Simulation into Nursing Curricula. International Journal of Nursing Education Scholarship. 2008; 5(1): Article 13. http://dx.doi.org/10.2202/1548-923X.1567

[18] Bond W, Lammers R, Spillane L, Smith-Coggins R, Fernandez R, Reznek M,et al. The use of simulation in emergency medicine: A research agenda. Academic Emergency Medicine. 2007; 14(4): 353-364. PMid:17303646

http://dx.doi.org/10.1111/j.1553-2712.2007.tb02021.x

[19] Terman KA. Clinical simulation laboratories and the clinical nurse specialist.Clinical Nurses Specialitst. 2007; 21(2): 66-67. http://dx.doi.org/10.1097/00002800-200703000-00003

[20] Leighton K, Scholl K. Simulated codes: Understanding the response of undergraduate nursing students. Clinical Simulation in Nursing. 2009; 5(5): 187-194. http://dx.doi.org/10.1016/j.ecns.2009.05.058 
[21] Andreatta P. Saxton E, Thompson M. et al. Simulation-based mock codes significantly correlate with improved pediatric patient cardiopulmonary arrest survival rates. Pediatric Critical Care Medicine. 2011; 12(1): 33-38. PMid:20581734 http://dx.doi.org/10.1097/PCC.0b013e3181e89270

[22] Blakely TG. Implementing newborn mock codes. The American Journal of Maternal/Child Nursing. 2007; 32(4): $230-235$. PMid:17667287 http://dx.doi.org/10.1097/01.NMC.0000281962.56207.44

[23] Hunt EA, Fiedor-Hamilton M, Eppich WJ. Resuscitation education: Narrowing the gap between evidence-based resuscitation guidelines and performance using best educational practices. Pediatric Clinics of North America. 2008; 55: 1025-1050. PMid:18675032 http://dx.doi.org/10.1016/j.pcl.2008.04.007

[24] Villamaria FJ, Pliego JF, Wehbe-Janek H, Coker N, Rajab MH, Sibbitt S, et al. Using simulation to orient code blue teams to a new hospital facility. Simulation in Healthcare. 2008; 3: 209-216. PMid:19088665 http://dx.doi.org/10.1097/SIH.0b013e31818187f3

[25] Hunt EA, Walker AR, Shaffner DH, Miller MR, Pronovost PJ. Simulation of in-hospital pediatric medical emergencies and cardiopulmonary arrests: Highlighting the importance of the first 5 minutes. Pediatrics. 2008; 121: e34-e43. PMid:18166542 http://dx.doi.org/10.1542/peds.2007-0029

[26] Banks D, Trull K. Optimizing patient resuscitation outcomes with simulation. Nursing2012. 2012; 28(3): 60-61.

[27] Huseman KF. Improving code blue response through the use of simulation. Journal of Nursing Staff Development. 2012; 28(3): 120-124. PMid:22617782 http://dx.doi.org/10.1097/NND.0b013e3182551506 